\title{
AKUATORIUM: MENUJU ALTERNATIF KREMASI YANG LEBIH HIJAU
}

\author{
Jeremy Edbert Jingga ${ }^{1)}$, Sutarki Sutisna ${ }^{2)}$ \\ 1)Program Studi S1 Arsitektur, Fakultas Teknik, Universitas Tarumanagara, jeremyedbertj@gmail.com \\ 2) Program Studi S1 Arsitektur, Fakultas Teknik, Universitas Tarumanagara, sutarkis@gmail.com
}

Masuk: 10-07-2021, revisi: 30-07-2021, diterima untuk diterbitkan: 23-10-2021

\begin{abstract}
Abstrak
Masyarakat Indonesia sangat heterogen sehingga masyarakat Indonesia mengenal berbagai jenis adat istiadat dan tradisi, tidak terkecuali prosesi pemakaman. Indonesia mengenal 6 agama sehingga ada 2 jenis prosesi pemakaman di Indonesia, yaitu kremasi dan penguburan. Namun, semakin berkurangnya lahan di kota Bandung untuk pemakaman, menimbulkan isu keterbatasan lahan pemakaman. Selain itu, kremasi konvensional juga sangat tidak ramah lingkungan karena menghasilkan berbagai polusi udara, sehingga diperlukan alternatif yang lebih ramah lingkungan. Sudah dikembangkan teknik akuamasi yang memanfaatkan air sebagai alternatif kremasi yang lebih ramah lingkungan. Proyek ini juga harus memiliki nilai simbolik yang universal dan dalam sehingga tidak mengurangi aspek sakral dari prosesi pemakaman jenazah. Maka dari itu, nilai simbolik universal ini akan dituangkan melalui tema arsitektur sakral yang dicapai menggunakan metode fenomenologis dan arsitektur paradoks jukstaposisi. Dengan menggunakan metode tersebut, proyek ini dapat memenuhi nilai simbolik universal dari pemakaman, serta akuamasi dapat menjadi alternatif kremasi konvensional sebagai pemenuhan dari "Beyond Ecology", sehinggapermasalahan lingkungan dapat terselesaikan.
\end{abstract}

Kata kunci: Akuatorium; Fenomenologi; Kuburan; Jukstaposisi; Rumah Abu.

\begin{abstract}
The heterogeneity of the Indonesian people results in various traditions and beliefs, including death procession. The people of Indonesia acknowledge six religions, and because of this cremation and burial are two widely accepted death processions. Despite so, the rapid decrease of land availability for cemetery usage results in the scarcity of land for cemeteries. Moreover, conventional cremation creates environmental problems like air pollution, so a much more environmentally friendly alternative is direly needed. Aquamation is a newer and more environmental-friendly technique of death procession that can serve as an alternative to conventional cremation by utilizing water. This project's aim is to answer the contextual and environmental issue in Bandung. At the same time, this project has to have a deep universal symbolic value so this project doesn't reduce the sacred aspects of the funeral process. With that in mind, this universal value will be expressed through the concept of sacred architecture through phenomenology and juxtaposed paradox methods. Using such methods, the universal symbolic value can be fulfilled and aquamation can be an alternative to conventional cremation as a "Beyond Ecology" fulfillment, so that the contextual environmental problem can be solved.
\end{abstract}

Keywords: Aquatorium; Cemetery; Columbarium; Juxtaposition; Phenomenology.

\section{PENDAHULUAN}

\section{Latar Belakang}

Masyarakat Indonesia yang heterogen menyebabkan suku, agama dan ras masyarakat Indonesia sangat beragam. Keberagaman ini berakibatkan pada beragamnya tradisi, adat dan kebiasaan yang dianut, tidak terkecuali di dalamnya upacara prosesi pemakaman. Masyarakat Indonesia mengakui enam agama, sehingga mengenal dua jenis prosesi pemakaman, yaitu kremasi dan penguburan. 
Kremasi konvensional sangat tidak ramah lingkungan karena boros energi. Selain itu, kremasi konvensional menghasilkan emisi karbon monoksida dan merkuri yang dapat menyebabkan polusi udara. Lahan pemakaman di Bandung sudah $96 \%$ terisi penuh, padahal kuburan merupakan suatu kebutuhan suatu kota karena kematian tidak bisa dipisahkan dari kehidupan. Terakhir, kota Bandung sebagai dataran tinggi juga masih dilanda problema banjir.

Akuamasi merupakan teknik kremasi baru menggunakan air dan larutan senyawa akuamasi. Teknik ini lebih ramah lingkungan karena menggunakan energi listrik yang jauh lebih rendah, dan tidak menghasilkan emisi merkuri sama sekali. Hasil outputnya tetap sama, yaitu abu ditambah larutan air. Larutan air ini dapat digunakan sebagai penyubur tanaman. Untuk kuburan diberlakukan teknik biopori untuk menambah daya resap tanah sehingga mengurangi banjir.

\section{Rumusan Permasalahan}

a. Bagaimana alternatif prosesi pemakaman yang lebih hijau?

b. Bagaimana menyelesaikan masalah keterbatasan lahan untuk pemakaman di Bandung?

c. Bagaimana cara untuk menyelesaikan masalah banjir di kota Bandung?

d. Bagaimana cara merancang suatu proyek yang berkaitan dengan kematian tanpa mengurangi aspek sakral proyek tersebut?

e. Bagaimana cara merancang pada kontur tapak yang ekstrim?

f. Bagaimana perancangan sistem mekanikal-elektrikal-plumbing (MEP) sehingga tidak merusak lingkungan?

\section{Tujuan}

a. Bagi Bidang Keilmuan: Menjelaskan proses akuamasi serta menjelaskan sistem MEP yang cocok untuk teknik akuamasi sehingga tidak menimbulkan permasalahan lingkungan yang baru.

b. Bagi Instansi Terkait: Memulai trend usaha akuamasi sehingga penyedia jasa prosedur akuamasi mulai banyak.

c. Bagi Masyarakat: Memberikan penyuluhan yang informatif mengenai alternatif kremasi konvensional yang lebih ramah lingkungan, serta menyelesaikan masalah lingkungan kontekstual kota Bandung.

\section{KAJIAN LITERATUR}

\section{Fenomena dan Latar Belakang Masalah}

Menurut Dinas Kependudukan dan Pencatatan Sipil Kota Bandung sendiri, tercatat ada sekitar 2,385,028 jiwa di kota Bandung. Membandingkan jumlah tersebut dengan demografi masyarakat kota Bandung yang sangat heterogen, dapat disimpulkan masyarakat kota Bandung terdiri dari suku, agama dan ras yang berbeda-beda. Keberagaman masyarakat kota Bandung ini pastinya akan berujung pada kepercayaan, adat dan tradisi yang berbeda-beda dalam berbagai tindakan dan rutinitas kehidupan mereka. 
Gambar 1. Tabel Demografi Penduduk Bandung Menurut Agama

Sumber: Dinas Kependudukan dan Pencatatan Sipil Kota Bandung 2018

Tabel di atas menunjukkan bahwa dari 6 agama yang diakui di Indonesia, agama Islam merupakan agama mayoritas di kota Bandung, dengan persentase yang hampir mencapai angka 92\% (Dinas Kependudukan dan Pencatatan Sipil Kota Bandung, 2018). Selanjutnya, didapat bahwa ada 13 TPU di Bandung yang sudah 96\% terisi penuh, padahal angka kematian kota Bandung mencapai 6,600 jiwa/tahun. Sehingga, dengan angka tersebut diproyeksikan bahwa pada tahun 2021 lahan pemakaman di kota Bandung akan habis (Alam, 2012). Padahal, kematian adalah sebuah bagian dari tahapan kehidupan sehingga kematian tidak dapat dihindari, menjadikan proses pemakaman suatu kebutuhan suatu kota.

Mengaitkan proses pemakaman dengan heterogenitas agama masyarakat kota Bandung, perbedaan kepercayaan memiliki pemandangan berbeda dengan proses pemakaman. Maka dari itu, kota Bandung mengenal 2 proses pemakaman, yaitu penguburan dan kremasi.

Kota Bandung terletak di dataran tinggi namun tidak terluput dari fenomena banjir. Kota Bandung ini memiliki kedudukan $768 \mathrm{~m}$ di atas permukaan laut. Kasus banjir kota Bandung terakhir tercatat di akhir bulan Desember 2020. Fenomena banjir ini disebabkan oleh meluapnya sungai Citarum dan intensitas curah hujan yang sangat tinggi.

\section{Issue Lingkungan Kremasi Konvensional}

Selain penguburan, alternatif pemakaman yang biasa digunakan adalah kremasi. Namun, kremasi konvensional membutuhkan energi yang sangat besar untuk memanaskan krematorium mencapai suhu 760-1000 derajat Celsius selama berjam-jam.

Selain itu, proses kremasi juga menghasilkan sejumlah polusi udara, mulai dari emisi zat merkuri dan gas karbon monoksida ke udara yang dapat memperburuk keadaan efek rumah kaca. Sudah jelas kremasi konvensional memberikan cukup banyak dampak buruk bagi lingkungan, dan mengingat cukup tingginya penggunaan jasa kremasi dalam kebiasaan orang Indonesia, dapat menjadi kontributor polusi di Indonesia yang cukup harus diperhatikan.

\section{Akuamasi}

Akuamasi merupakan teknik kremasi dengan menggunakan air, yaitu dengan memasukkan tubuh orang ke dalam tabung akuamasi yang kemudian diberi air, senyawa potassium hidroksida dan dipanaskan pada kondisi yang bertekanan tinggi. Teknik ini menggunakan proses hidrolisis alkali.

Hasil output dari proses akuamasi ini sama dengan proses kremasi konvensional, yaitu abu yang dapat dikumpulkan dan diserahkan kepada keluarga/kerabat orang yang sudah mati. Selain abu, hasil output lainnya dari proses ini adalah larutan senyawa potassium hidroksida yang kemudian dapat dibuang. 
Lebih detail lagi, proses akuamasi ini adalah sebagai berikut, pertama-tama, tubuh dimasukkan ke dalam tabung akuamasi. Setelah itu, tabung diisi tekanan, air dan potassium hidroksida, kemudian tabung dipanaskan dan proses akuamasi berjalan. Selanjutnya, hasil larutan buangan didinginkan, sedangkan hasil tulang belulang dihancurkan dan disimpan dalam guci. Terakhir, hasil larutan dibuang.

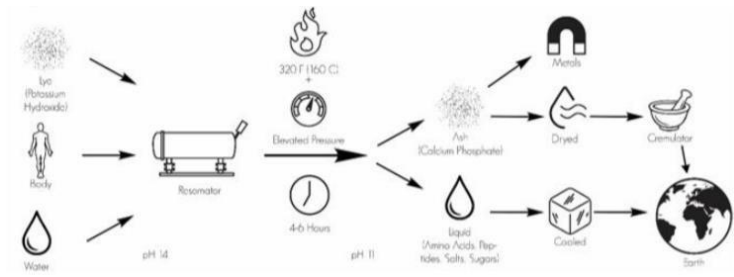

Gambar 2. Proses Akuamasi

Sumber: Morley, 2021.

Satu kali proses akuamasi membutuhkan sekitar 1500 liter air dan menghasilkan sekitar 1100 liter air. Dengan jumlah ini, mengingat air hasil output proses akuamasi dapat diolah dan digunakan kembali, netto air yang hilang terpakai adalah 400 liter air.

\section{Biopori}

Biopori adalah lubang resapan yang dibuat ditanam di bawah tanah. Sampah organik diletakkan di dalamnya sebagai makanan bagi tumbuhan dan cacing di sekitarnya. Lubang resapan ini nantinya akan dilubangi sehingga lebih mudah bagi sampah organik untuk terdegradasi.

Jasad yang dimakamkan ini nantinya akan diterapkan prinsip biopori, agar jasad tersebut bisa berguna bagi lingkungan. Keuntungan dari penggunaan prinsip biopori ini adalah biopori dapat menyuburkan tanah. Biopori juga dapat meningkatkan daya resap air, sehingga secara tidak langsung mengurangi kemungkinan banjir.

\section{Rumah Abu}

Rumah abu merupakan tempat penghormatan bagi orang yang sudah meninggal dan telah dikremasi dan biasanya abu jenazahnya disimpan dalam sebuah pasu, yaitu sebuah guci yang menyimpan sisa kremasi almarhum. Istilah lain dari rumah abu sendiri adalah "kolumbarium", yang berasal dari bahasa Latin columba yang berarti burung merpati dan awalnya merujuk pada perumahan yang diperuntukkan untuk burung merpati yang disebut dovecote.

\section{METODE}

Data yang didapat untuk proyek ini didapat dari sumber primer maupun sumber sekunder. Sumber primer didapat dari tinjauan data eksisting melalui analisis tapak yang dilakukan lewat Google Maps. Data sekunder didapat dari tinjauan data lewat berbagai sumber bacaan seperti buku, karya tulis, jurnal, makalah, e-book, dan lainnya.

\section{DISKUSI DAN HASIL}

\section{Analisis Lokasi Tapak}

a. Deskripsi singkat lokasi tapak

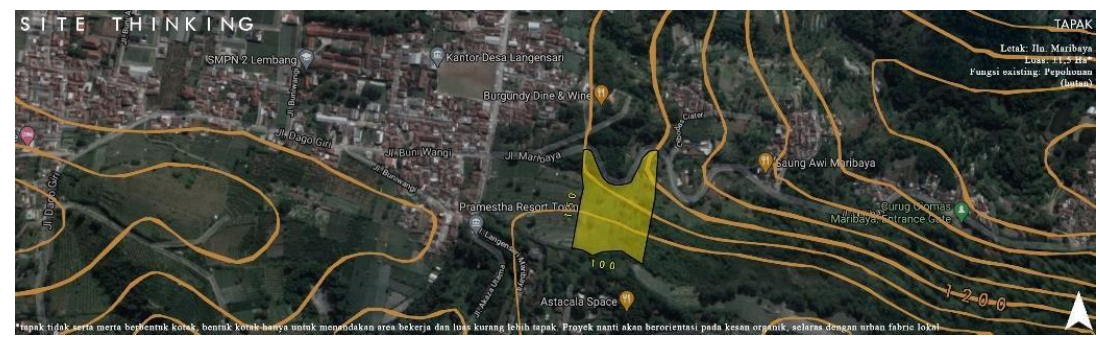

Gambar 3. Lokasi Tapak

Sumber: google.com 
Lokasi tapak yang seluas 1,5 Ha $\left(15000 \mathrm{~m}^{2}\right)$ berada di Jalan Maribaya dan terletak di Desa Langensari, Kecamatan Lembang, Kabupaten Bandung Barat. Fungsi existing tapak adalah lahan pepohonan yang masih kosong.

\section{b. Alasan pemilihan tapak}

Tapak harus berada di daerah peri-urban dengan tingkat kepadatan penduduk rendah sampai sedang, sesuai dengan fungsi proyek yaitu kuburan. Hal ini dilakukan agar fungsi pemakaman tidak mengganggu aktivitas sehari-hari warga sekitar. Tapak harus mudah diakses mobil jenazah dan mobil pribadi karena fasilitas publik, sehingga kondisi jalan harus dalam keadaan baik dan lebar. Terakhir, karena area target pelayanan bangunan ini adalah kota Bandung maka tapak tidak boleh jauh dari kota Bandung.

Dari ketiga bahan pertimbangan di ataslah ditentukan bahwa proyek akan didirikan di Desa Langensari, Lembang, yang merupakan sebuah kawasan peri-urban terletak $12 \mathrm{~km}$ dari kota Bandung. Tapak yang dipilih terletak di Jalan Maribaya karena jalan ini sudah tergolong cukup baik dan dapat dilalui kendaraan pribadi maupun mobil jenazah. Selain itu tapak ini juga cukup jauh dari pemukiman penduduk sehingga tidak akan mengganggu aktivitas penduduk setempat.

\section{c. Analisis Tapak}

\section{Analisis Aksesibilitas}

Di Desa Langensari, terdapat dua tipe jalan, yaitu jalan utama dan jalan desa. Jalan utama umumnya sudah dalam kondisi yang baik, seperti sudah beraspal, memiliki penerangan dan rambu lalu lintas yang sudah memadai. Jalan utama juga memiliki lebar yang cukup untuk 2 lajur (masing-masing 1 jalur). Jalan utama yang terletak di sisi jurang juga sudah diberi pagar pembatas sebagai pengaman.

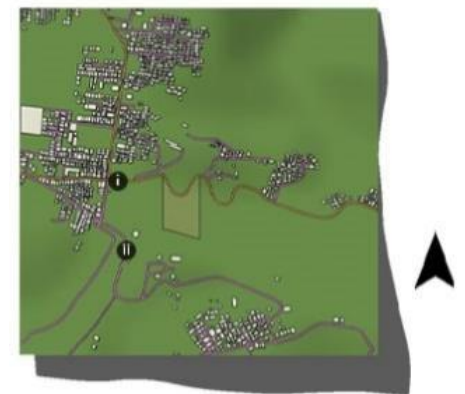

Gambar 4. Analisis Aksesibilitas

Sumber: Jingga, 2021

\section{Analisis Kontur}

Titik terendah tapak berada pada ketinggian $1200 \mathrm{~m}$ di atas permukaan laut, sedangkan titik tertinggi tapak berada pada ketinggian $1250 \mathrm{~m}$ di atas permukaan laut. Tapak cukup terjal/curam dengan perbandingan antara panjang dan elevasi 1:3 sehingga akan digunakan sistem cut and fill untuk membangun.

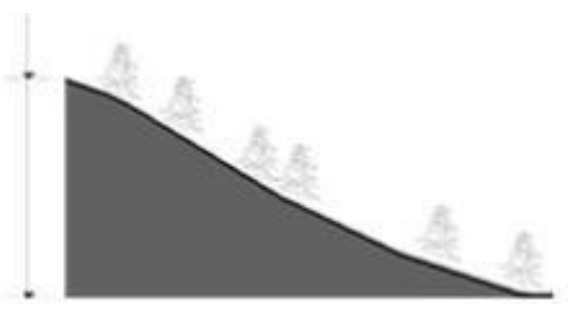

Gambar 5. Analisis Kontur Sumber: Jingga, 2021 
Analisis Zonasi dalam Tapak

Zonasi paling depan tapak dijadikan zona parkir karena letaknya yang dekat dengan akses masuk tapak. Bentuk depan tapak yang cukup sulit juga sebaiknya dimanfaatkan sebagai parkir dan landscaping karena bersifat fleksibel. Zona tengah menjadi area bangunan. Zona paling belakang tapak menjadi area lahan pemakaman karena titik letaknya berada di titik tertinggi tapak, sehingga esensinya area kuburan ini sebagai tempat untuk mengantar jasad orang mati yang sudah selesai tugasnya di dunia ke keabadian.

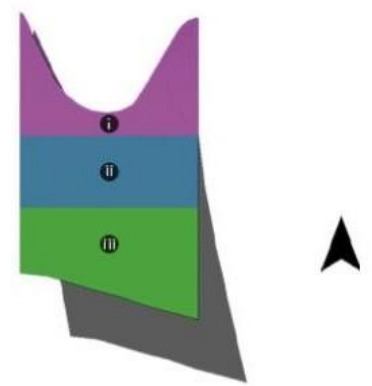

Gambar 6. Analisis Zonasi dalam Tapak

Sumber: Jingga, 2021

Analisis Air Hujan

Kontur tapak yang menanjak curam dan ekstrim memerlukan sistem pengaliran air hujan yang jelas sehingga air hujan tidak akan tergenang di satu titik, juga agar tidak banjir.

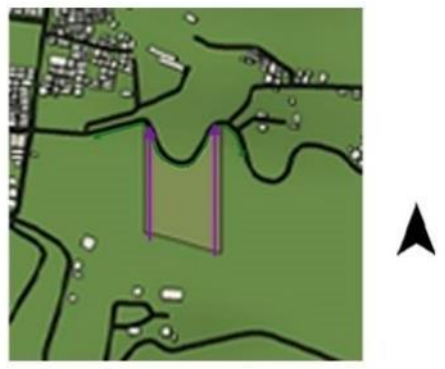

Gambar 7. Analisis Aliran Air Hujan

Sumber: Jingga, 2021

Air hujan akan dialirkan menuju water treatment plant sehingga air bekas proses akuamasi serta air hujan diolah lalu dialirkan menuju ground water tank sehingga air tersebut bisa digunakan kembali untuk kebutuhan kamar mandi maupun proses akuamasi selanjutnya. Air hujan tersebut akan mengalir melalui tapak menggunakan talang beton yang ditutup oleh grating besi.

\section{Analisis Program Kegiatan}

a. Analisis Pengguna Ruangan

Secara mendasar, kategori pengguna ruangan ini terbagi menjadi dua, yaitu pengunjung dan pengelola serta staff bangunan. Pengunjung termasuk pengunjung akuatorium, pengunjung area pemakaman serta pengunjung rumah abu.

Pengelola serta staff bangunan meliputi petugas pemakaman, petugas pengurus proses akuamasi, petugas kebersihan, pengurus rumah abu, pengelola akuatorium, penjaga toko guci, penjaga serta koki kafe dan petugas maintenance.

b. Analisis Kegiatan

Dua kegiatan utama pada proyek ini adalah kegiatan akuamasi serta kegiatan berziarah. Kegiatan utama akuamasi didukung kegiatan pendukung seperti membeli guci, menunggu di kafe, beribadah, dsb. Kegiatan utama selanjutnya adalah berziarah dan berdoa, baik di pemakaman maupun rumah abu. Tentunya kegiatan ini didukung oleh kegiatan pengelola seperti berjualan di kafe, mengelola mesin akuamasi, dsb. 


\section{Analisis Konsep dan Bentuk Perancangan}

a. Fenomenologi (Heidegger)

Teori fenomenologi Heidegger serta konsep fourfold-nya dalam buku Building Dwelling Thinking jika dituangkan ke dalam ilmu arsitektur secara mentah-mentah tidak selaras dengan ilmu arsitektur, karena sejatinya ilmu arsitektur berkaitan erat dengan pekerjaan profesional, ilmu eksakta, serta aspek estetika, semua yang dianggap Heidegger sudah meracuni pemikiran manusia di jaman modern ini.

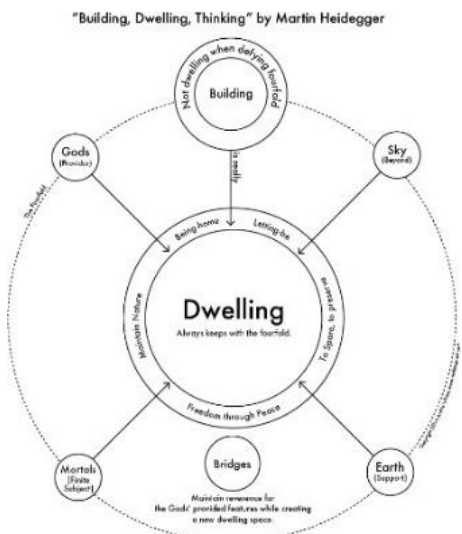

Gambar 8. Konsep Fourfold Heidegger

Sumber: https://uiarch.net/site/assets/files/5841/martin-heidegger.png

Padahal, teori Heidegger ini sangat menarik untuk diterapkan dalam dunia arsitektur, khususnya konsep fourfold, yang sudah seharusnya selalu menjadi aspek wajib yang diikutsertakan dalam setiap rancangan arsitektur. Hal ini disebabkan karena isu kerusakan alam yang semakin bobrok. Dengan menerapkan konsep fourfold Heidegger, manusia dapat merancangkan karya-karya arsitektur yang menghormati dan selaras dengan alam, sehingga pada akhirnya manusia dapat berdamai dengan alam.

\section{b. Arsitektur Fenomenologis}

Fenomenologi dalam arsitektur adalah sebuah konsepsi arsitektur yang menekankan pada pengalaman penghuni ataupun pengunjungnya. Fenomenologi dalam arsitektur adalah sebuah filsafat yang menekankan pada pengalaman individual. Pengalaman individual kemudian menjadi pengalaman yang terbagikan, menjadi pengalaman sosial (Gunawan, 2012:51).

Lebih lanjut lagi, arsitektur fenomenologis sering diintepretasi secara berbeda-beda oleh arsitek yang berbeda. J. Pallasmaa dalam tulisannya yang berjudul 'An Architecture of the Seven Senses' mengajukan berbagai pengalaman sebagai metafora dari pengalaman meruang tubuh manusia (Gunawan, 2012:55).

Juhani juga mengkritik bahwa arsitektur modern bersifat okulersentris, sehingga menurutnya arsitektur modern ini mulai menumpulkan indera manusia lainnya. Menurut Mark Peterson, arsitektur multi-sensory tidak bisa dialami hanya menggunakan indera penglihatan saja, namun harus melibatkan seluruh panca indera untuk merasakan pengalaman tersebut (Tamari, 2017).

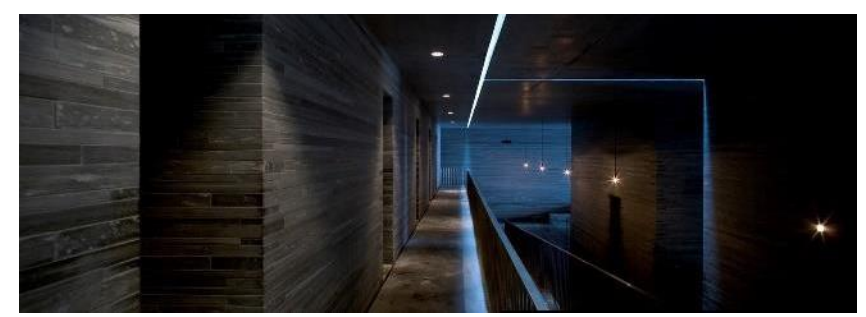

Gambar 9. Therme Vals oleh Peter Zumthor dan

Penerapan Fenomenologi Melalui Suasana Ruang

Sumber : https://images.adsttc.com/media/images/580f/b3d4/e58e/cefd/6700/008f/slideshow/32.jpg 
Dari pemaparan di atas, dapat disimpulkan bahwa arsitektur fenomenologis adalah sebuah filsafat arsitektur yang menekankan pada pengalaman individual penghuni ataupun pengunjungnya yang ditimbulkan oleh suatu atmosfir dan suasana yang dirasakan oleh keseluruh indera manusia dan tidak berfokus pada indera penglihatan saja.

\section{c. Arsitektur Sakral}

Arsitektur sakral sudah berubah terminologinya. Arsitektur sakral yang tadinya berkaitan erat dengan kegiatan religius (gereja, katedral, masjid, dst), tidak lagi selalu diasosiasikan dengan kegiatan religius, tapi sebagai sebuah karya yang memancing perasaan, pemikiran dan refleksi. Hal ini menyebabkan program ruang atau fungsi bangunan sudah tidak lagi mendefinisikan sakral.

Atmosfir sakral harus bisa berhubungan dengan penghuni pada level spiritual dan emosional. Contohnya dengan menggunakan suatu material, menghasilkan suatu tekstur, suhu, gaung, dan lainnya. Atmosfir inilah yang nantinya akan menjadi pemrakarsa dari pengalaman spiritual dan emosional itu sendiri.

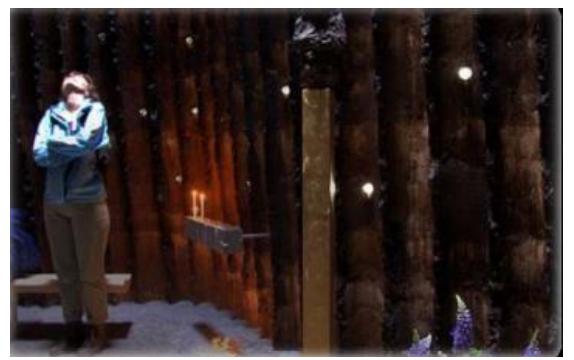

Gambar 10. Bruder Klaus Chapel sebagai arsitektur sakral Sumber: pia.sjtu.edu.cn/2008/PDF1/31-Bruder\%20klaus.pdf

d. Kaitan Arsitektur Fenomenologis dengan Arsitektur Sakral

Fenomenologi dalam arsitektur dan arsitektur sakral sama-sama menawarkan hal yang serupa, yaitu arsitektur yang menekankan pada pengalaman individual yang ditimbulkan oleh suasana atmosfir keruangan. Suasana atmosfir keruangan ini dapat dicapai melalui penggunaan material tertentu serta manipulasi elemen ruangan tertentu sehingga menghasilkan suatu suasana yang memancing pemikiran, mengunggah perasaan dan menciptakan pengalaman.

Suasana yang dihasilkan pada arsitektur sakral dan metode perancangan fenomenologi terbentuk atas berbagai manipulasi aspek keruangan. Suasana sakral ini sesuai dengan pernyataan Peter Zumthor, sangat menitikberatkan pada suasana dan atmosfir yang dirasakan terhadap sense of touch. Sense of touch ini paling bisa dirasakan melalui materiality yang memanipulasi suhu (The Temperature of Space) dan pencahayaan (The Light on Things) (Zumthor, 2006).

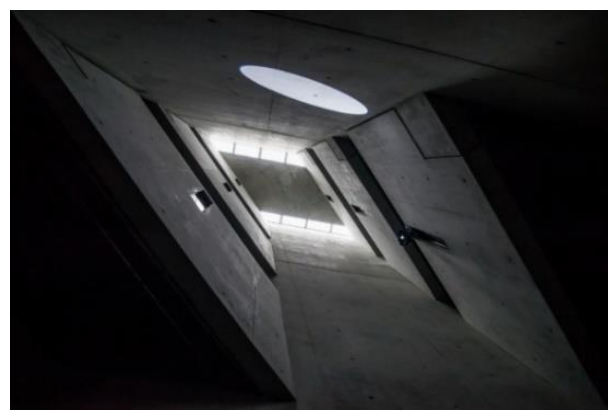

Gambar 11. Jewish Museum Berlin Sebagai Penerapan Arsitektur Fenomenologis dan Sakral

Sumber: archdaily.com/91273/ad-classics-jewish-museum-berlin-daniel-libeskind

Jadi, dalam penciptaan atmosfir sakral, dua elemen yang memegang peran paling penting untuk 
menghadirkan "sakral dingin" tersebut adalah lewat pencahayaan serta materialitas bangunan.

\section{e. Arsitektur Jukstaposisi}

Kata jukstaposisi menurut kamus Besar Bahasa Indonesia (KBBI) adalah penempatan dua objek secara berdampingan, sedangkan menurut kamus Oxford adalah dua hal yang dilihat atau ditempatkan berdekatan sehingga kontras/mencolok.

Bidang arsitektur selalu berkaitan dengan penempatan ruang/tempat yang berdampingan sebagai manifestasi dari perbedaan (Laiprakobsup, 2007). Aldo van Eyck menambahkan bahwa hal tersebut merupakan arsitektur timbal balik yang mengharmonisasikan perbedaan.

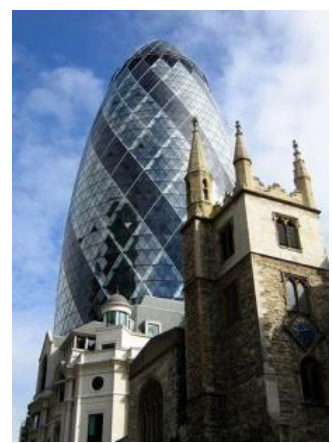

Gambar 12. Gherkin yang terjukstaposisi dengan bangunan seragam di sekitarnya

Sumber: https://i.pinimg.com/originals/90/9c/a9/909ca9939418943401920f99d4345d32.jpg

Lebih dalam lagi, sebuah ruangan yang lebih "berhasil" menggunakan suatu kompleksitas yang berkontradiksi dalam penyusunannya dan persepsi keruangan dengan menciptakan suatu bentuk jukstaposisi lewat overlayering, transparansi serta ruangan yang menyurut (Cheesman, 1987).

Menurut Christopher Muscato, banyak elemen arsitektur yang dapat terjukstaposisi, mulai dari bentuk, letak bangunan, material, fungsi, dan seterusnya. Terkait dengan proyek ini, jukstaposisi yang diangkat adalah terkait fungsi bangunan, yaitu pemakaman dan rumah abu dengan krematorium. Pemakaman berkaitan erat dengan orang mati, sedangkan krematorium masih berhubungan dengan orang hidup. Dengan menggabungkan dua fungsi yang sangat berkontras ini, dapat dihasilkan suatu energi dan spasialitas ruangan yang berkesan bagi para pengunjung.

\section{f. Arsitektur Paradoks}

Menurut KBBI, arti kata paradoks adalah pernyataan yang seolah-olah bertentangan (berlawanan) dengan pendapat umum atau kebenaran. Sedangkan menurut kamus Oxford, arti kata paradoks adalah seseorang, sesuatu atau suatu kondisi yang memiliki sifat berlawanan. Pemikiran yang bersifat paradoks, membuka kesempatan untuk melihat dua aspek arsitektur, baik itu tipologi ataupun yang lainnya dalam satu komposisi yang mengejutkan (Chang, 2020). Dari uraian di atas, dapat disimpulkan bahwa arsitektur paradoks adalah konsep penggabungan dua elemen arsitektur yang berlawanan dan tidak masuk akal (namun belum tentu salah) sehingga menghasilkan suatu komposisi yang baru yang tepat. Arsitektur paradoks ini dapat dikaitkan dengan pengertian arsitektur jukstaposisi juga dimana dua-duanya menawarkan penggabungan dua elemen arsitektural yang berlawanan sehingga menciptakan kekontrasan satu dengan yang lainnya.

Pada proyek ini, diharapkan penggabungan antara aktivitas orang mati dan orang hidup, dua elemen arsitektural yang sangat kontras, dapat digabungkan sehingga menghasilkan suatu energi. Konsep paradoks ini berkaitan dengan stigma kuburan yang selalu identik dengan di bawah tanah dan stigma orang hidup di atas tanah. 
g. Square is the Earth and Round is the Heavens

Ada sebuah filosofiChina kunoyang berbunyi “Tian Yuan Di Fang” (天圆地方) yang berarti “Square is the Earth and Round is the Heaven", yang memiliki arti bahwa bumi dianalogikan berbentuk persegi dan surga dianalogikan berbentuk melingkar.

Analogi ini bermula dari kepercayaan orang China yang menganggap bahwa langit menutupi Bumi seperti payung (Teori Gai Tian) ataupun bola yang melingkari Bumi (Teori Hun Tian).

\section{Deskripsi Design}

\section{a. Sumbu Bangunan}

Sumbu bangunan mengiktui energi yang diciptakan oleh ruang GWT yang disamarkan menjadi paviliun ruang publik. Energi yang dimaksud di sini adalah air yang mengalir dari ruang GWT menuju ke Central Plaza. Energi ini menjadi sumbu orientasi utama proyek karena proyek ini sangat terkait dengan air. Dengan menjadi sumber energi utama proyek, keberadaan air ini akan terus dirasakan di seluruh proyek.

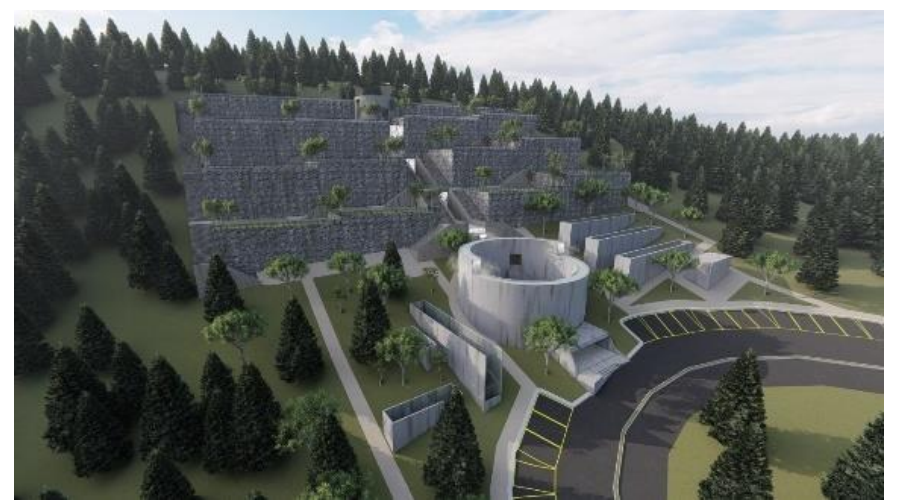

Gambar 13. Elemen Air Menjiwai Seluruh Proyek Sumber: Jingga, 2021

b. Bentuk Massing Bangunan

Massing Central Plaza berbentuk lingkaran sesuai dengan kepercayaan "Round is the Heavens". Diharapkan Central Plaza ini bisa merefleksikan kedamaian dan ketenangan surga lewat kehadiran kolam, air terjun serta pohonnya.

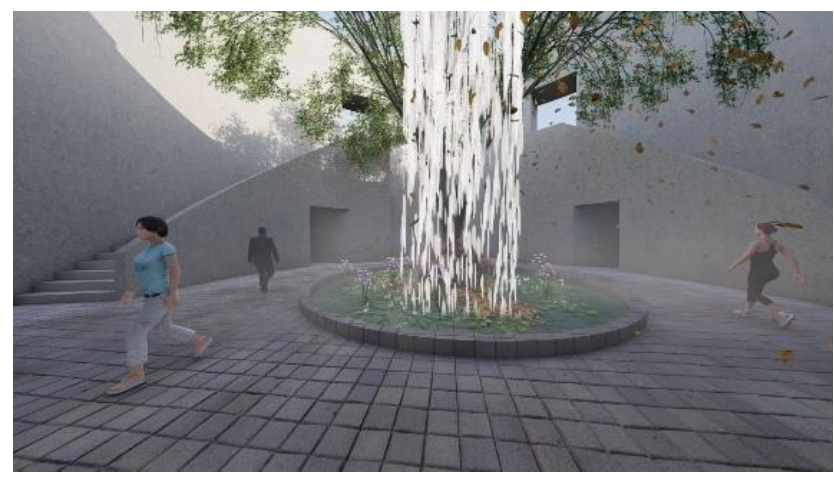

Gambar 14. Plaza of Heavens

Sumber: Jingga, 2021.

Sedangkan kedua massing akuatorium dan rumah abu mengambil bentuk persegi sesuai dengan kepercayaan "Square is the Earth" karena merupakan tempat aktivitas manusia hidup. Massing persegi ini lalu muncul dari permukaan tanah dengan susunan bertingkat dan diberi skylight agar seragam dengan area pemakaman yang terus menanjak, juga menyesuaikan dengan kontur tanah yang menanjak. 


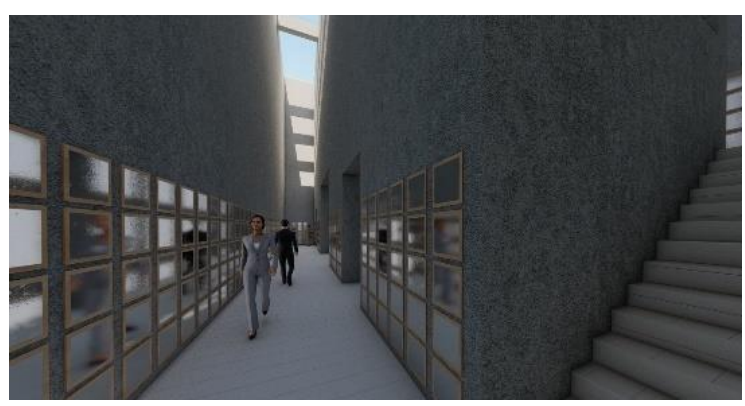

Gambar 15. Rumah Abu

Sumber: Jingga, 2021.

c. Teknis Bangunan

Struktur Bangunan

Bangunan dengan menggunakan struktur prinsip core bangunan, yaitu dinding dengan ketebalan $20 \mathrm{~cm}$. Dinding ini diperkuat dengan ring balok. Selain itu bangunan tidak menggunakan kolom struktur, hanya kolom praktis karena bangunan hanya dua lantai. Plat lantai bangunan setebal $12 \mathrm{~cm}$, namun plat lantai yang langsung berhubungan dengan tanah dibuat setebal $50 \mathrm{~cm}$.

\section{Sistem Drainase Hujan}

Karena kontur tapak yang cukup ekstrim, dibutuhkan suatu sistem pengaliran air hujan yang detail.

\section{- Storm Drain}

Pada bagian pemakaman di sisi kiri kanan tangga diberi storm drain (talang air beton bertulang $20 \mathrm{~cm}$ ) selebar $1 \mathrm{~m}$ dan sedalam $80 \mathrm{~cm}$ untuk menghindari penggenangan air. Air yang ditampung storm drain ini akan dialirkan menuju WTP untuk diolah sehingga bisa digunakan sebagai pasokan air bersih pada bangunan.

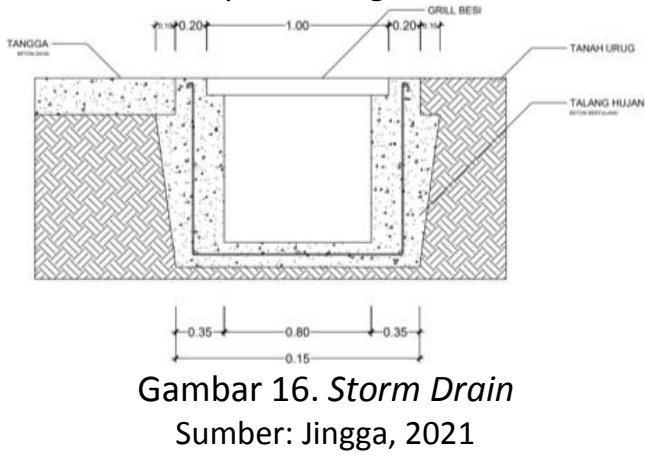

- Talang Air Hujan

Talang Air Hujan pada Permukaan Tanah

Pertemuan antara tanah berkontur serta dinding bangunan diberi talang air hujan beton bertulang dengan lebar $70 \mathrm{~cm}$ dan kedalaman $50 \mathrm{~cm}$. Hal ini untuk menghindari penggenangan di titik ini yang dapat merusak dinding beton. Talang ini dibangun mengelilingi dinding tersebut dan dicor menyatu dengan dinding utama bangunan sehingga kokoh, kemudian diberi tutup grill besi.

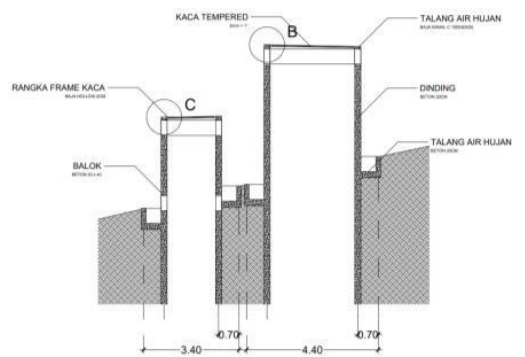

Gambar 17. Talang Air di Pertemuan Dinding dan Bangunan

Sumber: Jingga, 2021 


\section{Talang Air Hujan di Sekitar Skylight Bangunan}

Sisi atas dinding skylight yang lebih rendah (akibat kemiringan kaca $1^{\circ}$ ), dinding beton tersebut dicoak dan ditanam baja profil C 100×50×20 mm sebagai talang air hujan untuk mengalirkan air hujan yang mengalir turun ini dengan cara diangkur pada dinding beton tersebut.

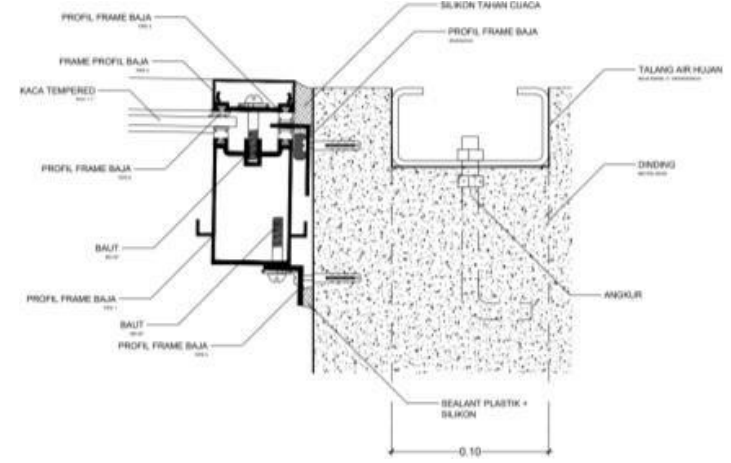

Gambar 18. Talang Air Baja

Sumber: Jingga, 2021

Di salah satu ujung baja profil C ini, diberikan storm drain yang kemudian disambungkan ke pipa plumbing air hujan berdiameter 3" yang berfungsi untuk mengalirkan air hujan yang telah ditampung menuju talang air hujan beton bertulang ditanah.

\section{Ruang Ibadah}

Pengaturan tempat duduk pada ruang ibadah berundak-undak dengan lebar $1 \mathrm{~m}$ dan perbedaan ketinggian $20 \mathrm{~cm}$, mengikuti prinsip aula/theater pada umumnya. Selain itu, untuk menghindari gema dinding ruangan dilapisi instalasi akustik yaitu acourete diffuser yang dibaut pada grid balok kayu. Untuk lantai dilapisi karpet juga untuk fungsi yang sama.

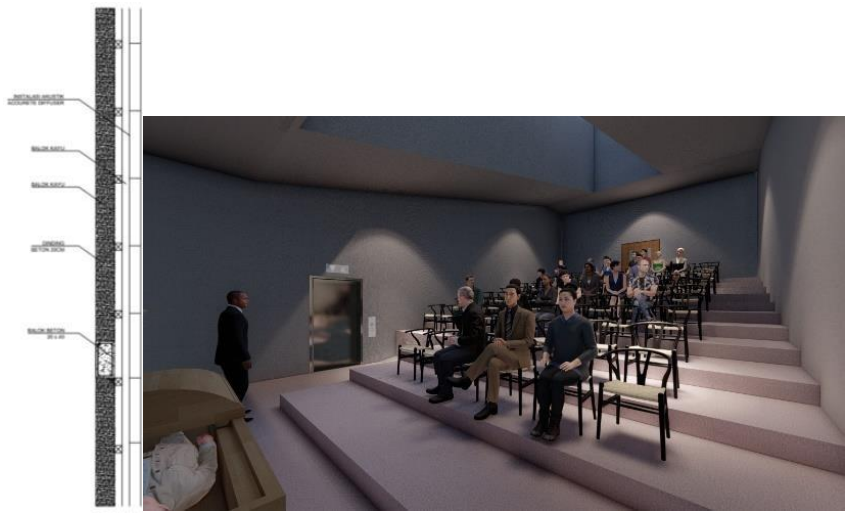

Gambar 19. Ruang Ibadah

Sumber: Jingga, 2021

\section{Ruang Akuamasi}

Ruang akuamasi diberikan sistem MEP khusus untuk mengatur sirkulasi dari tanki air panas dan tanki cairan kimia menuju mesin akuamasi. Tanki air panas mengambil pasokan air bersih dari GWT dan kemudian ditampung dalam tanki yang dipanaskan dengan heating coil listrik.

Pembuangan larutan hasil akuamasi juga diatur dimana larutan tersebut akan langsung dialirkan menuju WTP. Selain itu, hasil asap karbon monoksida dari mesin ini diproduksi oleh smoke generator, dan kemudian asap ini dibuang ke ducting udara kotor. 


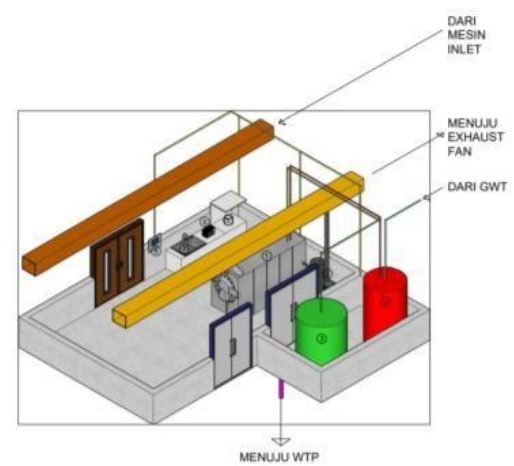

Gambar 20. Aksonometri R. Akuamasi

Sumber: Jingga, 2021

Terakhir, mesin akuamasi ini dilengkapi dengan wastafel, control panel, drying oven dan kremulator yaitu mesin penghancur abu.

Instalasi Skylight

Skylight pada bangunan dipasang dengan kemiringan $1^{\circ}$ untuk menghindari penggenangan air. Skylight terbuat dari kaca tempered $6 \mathrm{~mm}$ serta berbagai profil baja yang dibaut dan direkatkan dengan sealant. Frame ini kemudian dibaut ke dinding beton serta ring balok beton bertulang, tergantung dari letak kaca tersebut.
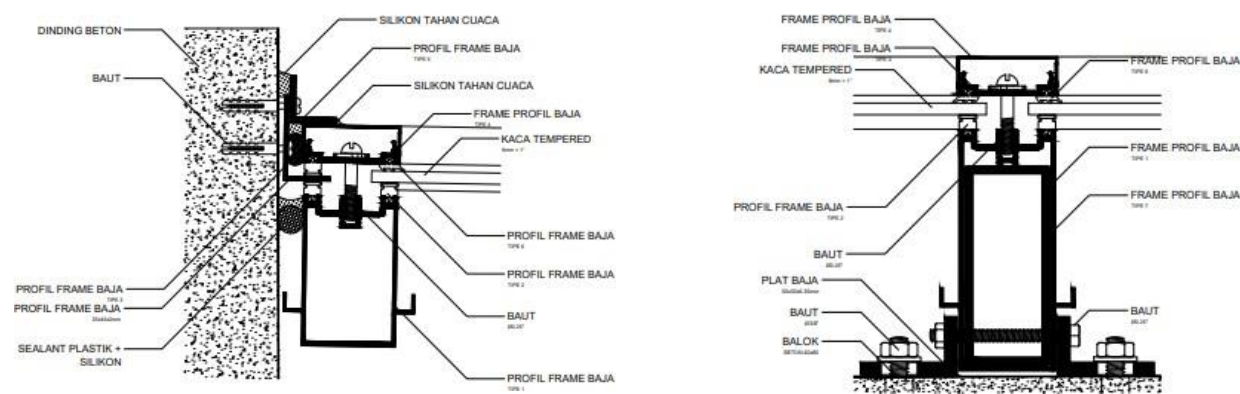

Gambar 21. Detail Skylight

Sumber: Jingga, 2021

Sistem MEP

Sistem Mekanikal

Sistem pengudaraan pada bangunan karena bersifat bawah tanah mengambil sistem pengudaraan basement. Tiap ruangan diperlengkapi dengan ducting udara bersih dan kotor. Ducting yang membawa udara bersih dari mesin inlet, sedangkan ducting udara kotor dialirkan menuju mesin exhaust fan. Kedua mesin ini menerima dan membuang udara bersih dan kotor dari dan menuju mesin ground exhaust serta inlet di atas tanah melalui shaft beton ducting utama.

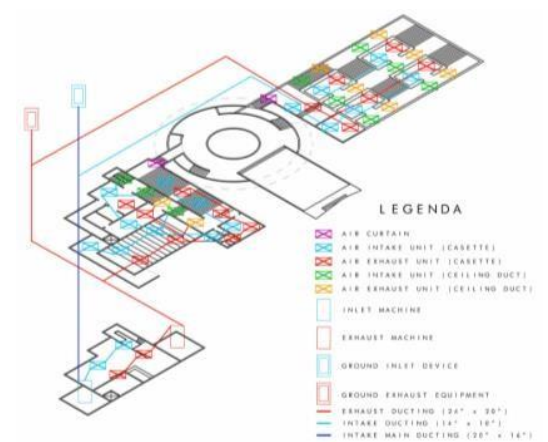

Gambar 22. Sistem Mekanikal Bangunan Sumber: Jingga, 2021 
Pada ruangan yang terdapat skylight yang mengharuskan pencahayaan maksimal maka mesin $A C$ indoor disiasati dengan cara diletakkan di ruangan sampingnya, yang kemudian dinding pemisah ruangan ini dicoak/dilubangi sehingga udara sejuk dapat mengalir keluar. Lubang ini akan diberi grill besi.

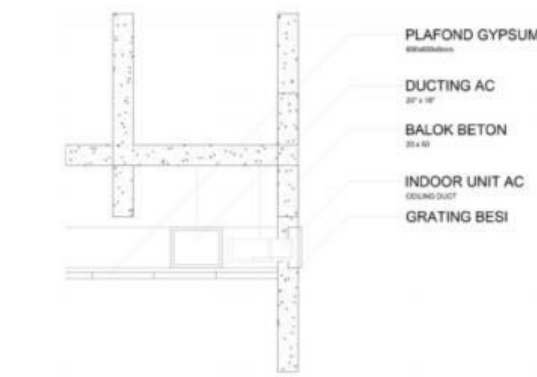

Gambar 23. Sistem Mekanikal Bangunan

Sumber: Jingga, 2021

Entrance antara akuatorium dan rumah abu dengan Central Plaza dimana sifat ruangan outdoor dan indoor diberi air curtain untuk mencegah terjadinya kebocoran udara/AC.

\section{Sistem Plumbing Air Kotor}

Plumbing air hasil akuamasi dialirkan menuju Water Treatment Plant (WTP) sehingga air tersebut dapat digunakan kembali sebagai air bersih. Plumbing air kotor (dari wastafel, air bekas cucian, dst) akan dialirkan menuju riol kota melalui pipa air berdiameter 2".

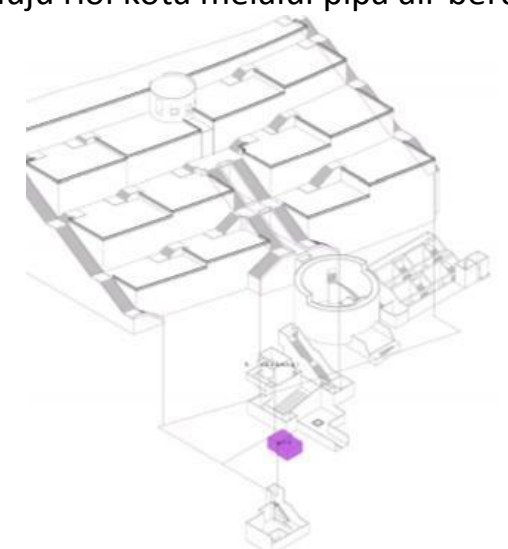

Gambar 24. Sistem Plumbing Air Kotor Sumber: Jingga, 2021

Sistem Cut and Fill Lahan Pemakaman (Terasering)

Lahan pemakaman yang berkontur sehingga diterapkan sistem cut and fill (terasering) untuk mencegah terjadinya longsor. Sistem ini juga akan menciptakan permukaan- permukaan yang rata sehingga berundak-undak, yang dapat digunakan sebagai lahan pemakaman.

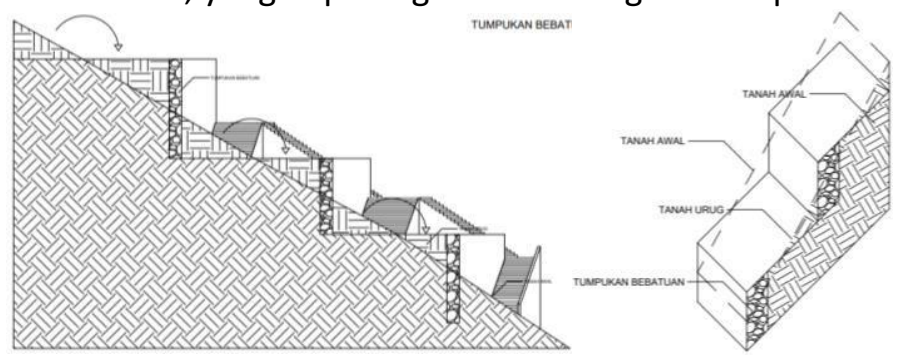

Gambar 25. Sistem Cut and Fill (Terasering)

Sumber: Jingga, 2021 


\section{KESIMPULAN DAN SARAN}

Kesimpulan

Proyek ini sudah cukup baik dalam menjawab rumusan permasalahan di awal dengan sistem MEP untuk pengaliran air hujan, pengolahan limbah hasil akuamasi serta sistem terasering untuk menyelesaikan kontur yang ekstrim. Selain itu, konsep fenomenologi serta jukstaposisi paradoks dapat memberikan nilai simbolik yang universal yang mendukung suasana pemakaman yang damai dan khidmat.

Meski begitu, penuangan konsep fenomenologi ke dalam proyek masih belum maksimal, khususnya dalam aspek pencahayaan, karena beragamnya jenis pencahayaan yang tidak harus selalu berasal dari sisi atas ruangan (skylighting).

\section{Saran}

Proyek ini memiliki keterbatasan pada bentuk kontur tapak yang sangat ekstrim, sehingga terkadang sering menjadi rintangan dalam merancang bangunan ini. Selain itu, bentuk tapak yang cukup tidak beraturan juga menjadi rintangan dalam perancangan.

\section{REFERENSI}

A guide to water cremation. (2019). Diakses 9 Juli 2021 dari https://www.funeralguide.co.uk/help- resources/arranging-a-funeral/funeral-guides/aguide-to-water-cremation

Alam, M. Fahmi Iskandar. (2012). Evaluasi penyediaan tempat pemakaman umum di kota Bandung. Bandung: Universitas Komputer Indonesia.

Baum, M. K. (2017). What is sacred. New York: Syracuse University of Architecture.

Badan Pusat Pengembangan dan Pembinaan Bahasa (n.d). Jukstaposisi (Def. 1). Dalam Kamus Besar Bahasa Indonesia (KBBI) Online. Diakses : 9 Juli 2021 dari https://kbbi.kemdikbud.go.id/entri/jukstaposisi

Badan Pusat Pengembangan dan Pembinaan Bahasa (n.d). Paradoks (Def. 1). Dalam Kamus Besar Bahasa Indonesia (KBBI) Online. Diakses 9 Juli 2021 dari https://kbbi.web.id/paradoks

Binggui, Z.. (2001). A general survey of cultural tradition of the Chinese cartography. Nanjing: Nanjing Surveying and Mapping Research Institute.

Chang, Y. C. N. (2020). Paradoxical architecture: an argument for the anti-logic and the absurd. Vancouver: University of British Columbia.

Cheesman, T. (1988). Dynamics of juxtaposition in architecture. Indiana: Ball State University. Cooke, Lacy. (2017). 'Water cremation' plans paused over fears liquefied remains could get in water system. Diakses 9 Juli 2021 dari https://inhabitat.com/water-cremation-planspaused-over-fears-liquefied-remains-could-get-in-water-system/resomation-watercremation/

Gunawan, U. (2012). Fenomenologi arsitektur; konsep, sejarah dan gagasannya. Jakarta: Universitas Muhammadiyah Jakarta.

Hardiman, F. B. (2016). Heidegger dan mistik keseharian. Jakarta: Kepustakaan Populer Gramedia.

Heidegger, M. (1951). Building dwelling thinking. Terjemahan: Adam Bobeck. Diakses 9 Juli 2021darihttps://www.academia.edu/34279818/Building_Dwelling_Thinking_by_Martin_ Heidegger_Translation_and_Commentary_by_Adam_Bobeck

Ladianto, A. J. (2016). Biopori: pemakaman vertikal masyarakat muslim Surabaya. Surabaya: Institut Teknologi Sepuluh Nopember Surabaya.

Laiprakobsup, N. (2007). Inbetween place: the emergence of the essence. Texas: Texas A\&M University.

Langi, J. S.P. dan Tinangon, A. J. (2012). Atmospheres - parameter desain Peter Zumthor dalam arsitektur. Manado: Universitas Sam Ratulangi.

Morley, D. (2020). Returning to the earth. lowa: lowa State University.

Muscato, C. Juxtaposition in architecture. Diakses 9 Juli 2021 
dari https://study.com/academy/lesson/juxtaposition-in-architecture.html

Oxford University Press. (n.d). Juxtaposition (Def. 1). Dalam Oxford Learner's Dictionaries Online.

Diakses

9

Juli

2021

dari

https://www.oxfordlearnersdictionaries.com/definition/english/juxtaposition

Resomation natural water cremation. (2021). Diakses 9 Juli 2021 dari https://resomation.com/ Sharr, Adam. (2007). Heidegger for architects. New York: Routledge.

Straight and Curved. (2010). 天圆地方: Round sky and square earth. Diakses 9 Juli 2021 dari http://scm-straight-curved.blogspot.com/2010/11/round-sky-and-square-earth.html

Tamari, T. (2017). The phenomenology of architecture: a short introduction to Juhani Pallasmaa. Diakses 9 Juli 2021 dari http://research.gold.ac.uk/id/eprint/19553/

Water cremation: is resomation a green \& bio friendly solution? (2019). Diakses 9 Juli 2021 dari https://cremationinstitute.com/water-cremation/

Zumthor, P. (2006). Atmospheres. Berlin: Birkhäuser Verlag AG. 